九州大学学術情報リポジトリ

Kyushu University Institutional Repository

\title{
Changes of the Moisture Content of Poplar Wood Samples Subjected to Roller Compression Treatment
}

WEN, Mingyu

Wood Material Science and Engineering Key Laboratory, College of Materials Science and Engineering, Beihua University

SUN, Yaoxing

Wood Material Science and Engineering Key Laboratory, College of Materials Science and Engineering, Beihua University

KANG, Chun-Won

Department of Housing Environmental Design, and Research Institute of Human Ecology, College of Human Ecology, Chonbuk National University

MATSUMURA, Junj $\mathrm{i}$

Division of Sustainable Bioresources Science, Department of Agro-environmental Sciences, Faculty of Agriculture, Kyushu University

https://doi.org/10.5109/4103901

出版情報: 九州大学大学院農学研究院紀要. 65 (2)，pp.357-363，2020-09. Faculty of Agriculture， Kyushu University

バージョン :

権利関係 : 


\title{
Changes of the Moisture Content of Poplar Wood Samples Subjected to Roller Compression Treatment
}

\author{
Mingyu WEN ${ }^{1}$, Yaoxing SUN ${ }^{1}$, Chun-Won KANG ${ }^{2}$ and Junji MATSUMURA ${ }^{3}$ \\ Laboratory of Wood Science, Department of Forest and Forest Product Science, \\ Faculty of Agriculture, Kyushu University, Fukuoka 812-8581, Japan \\ (Received April 2, 2020 and accepted May 27, 2020)
}

\begin{abstract}
Poplar (P.ussuriensis Kom) wood has been subjected to roller compression treatment with 10\%, 20\%, $30 \%, 40 \%$ and $50 \%$ of compression ratios in this study. The effects of water impregnating time, drying time and re-compression times on moisture content (MC) were investigated. The studies revealed that reduction in $\mathrm{MC}$ increased following the increasing of compression ratio. The MC reduction for tangential compression was found to be greater than that for radial compression. After 5 min impregnation in water, the ratio of $\mathrm{MC}$ decline of roller-compressed wood (RCW) samples tended to slow down. After impregnation for $95 \mathrm{~min}$, the $\mathrm{MC}$ of $\mathrm{RCW}$ was less than wood samples without treatment (untreated). In addition, during the dry process at $100^{\circ} \mathrm{C}$, the $\mathrm{MC}$ reduction for RCW samples was found to be greater than for untreated samples. Particularly, the drying time could be saved more than $20 \%$ with $50 \%$ compression ratio. Moreover, the MC of RCW samples subjected to 1, 3, 5, and 8 times re-compression treatment (RCT) was found to be reduced gradually for increasing re-compression times. The $\mathrm{MC}$ can be reduced half to the initial MC after 3 times re-compression, when the compression ratio was over $40 \%$.
\end{abstract}

Key words: Roller compression; Moisture content (MC); Ratio of MC decrease; Compression ratio; Roller re-compression times

\section{INTRODUCTION}

Removal of water from wood and the effectiveness of pretreatment processes are dependent on its permeability. Increasing the permeability of wood can increase the loss of moisture content (MC) and shorten drying times, and it also can increase the impregnation depth of chemicals such as preservative or fire retardant. Consequently, many studies have been carried out to improve the permeability of wood for promoting the penetration of liquid during treatments (Bao et al., 1999; Lv et al., 2000; He et al., 2014; Zhao et al., 2015b; Zhao, 2017).

Nair, HU et al. (1995) used a mixture of carbon dioxide and formaldehyde to study the effect of supercritical fluid treatment on the permeability of Pseudotsuga menziesii (Mirbel) Franco heartwood, which showed that the permeability of two-thirds of total samples was improved (Nair, andSimonsen, 1995). Keisuke (2011) used a laser incision method to treat Cryptomeria japonica D. Don, Chamaecyparis obtusa, Pseudotsuga menziesii var. and Tsuga chinensis pritz. They found that the impregnation level of laser incised woods with the modified liquid was 50\% greater than that of untreated wood samples (Keisuke, and Nobuaki, 2011). Bao et al. studied the permeability

\footnotetext{
Wood Material Science and Engineering Key Laboratory, College of Materials Science and Engineering, Beihua University, Jilin 132013 China

${ }^{2}$ Department of Housing Environmental Design, and Research Institute of Human Ecology, College of Human Ecology, Chonbuk National University, Jeonju 561-756, Korea

Division of Sustainable Bioresources Science, Department of Agro-environmental Sciences, Faculty of Agriculture, Kyushu University, Fukuoka 812-8581, Japan
}

of Yezo Spruce (Picea jezoensis var. microsperma) which stored in pond. After 10 weeks immersion, the permeability of sapwood was increased about 29 times, while the permeability of heartwood was found to increase unevenly (Bao, andLv, 1991; Bao, 1992). Nair et al. (1995) studied Douglas fir and Pinus ponderosa wood with compression treatment associated by acoustic waves. The combined treatment resulted in increasing in permeability of wood and absorption of chemical agents (Nair, andSimonsen, 1995). Wheat et al. (1996) also used ultrasonic technology to enhance the fluidity of liquid in wood (Wheat et al., 1996).

Prefreezing treatment has been used to reduce the shrinkage, collapse and drying degrade of wood for the drying of both hardwoods and softwoods, to increase the diffusion or the permeability of wood (Missio et al., 2015; Missio et al., 2016; Xu et al., 2018). Saturated steam blasting treatment uses steam as a pressurizing medium to soften the wood. Rapid reduction of the external pressure of the wood creates a pressure difference between the inside and outside of the wood, which can disrupt cell membranes and cell wall structures, resulting in the generation of new liquid flow channels (Zhang, andCai, 2006; Kvist et al., 2018). However, those techniques have not been fully explored and applied.

Pre-compression treatment is applied for separating and destroying aspirated pits in the wood during the compressive deformation process, leading to increased liquid uptake. Iida and Watanabe found that compression treatment could facilitate the wood drying and accelerate wood permeability for impregnation (Watanabe et al., 1998; Iida et al., 2002; Li et al., 2016). Zhao et al. studied compression treatment for wood drying. The effects of compression ratio, compression 
direction and compression speed on the reduction of MC and on mechanical properties, and the effects of MC during compression on the recovery rate (RR) of wood and on the mechanical properties were discussed. It was found that not only the MC of wood be very effectively reduced, but also the volume and the strength of wood could be rather well retained after the pre-treatment by compression. The wood volume and mechanical properties were well retained for the wood compressed at all MC conditions above fiber saturation point before and after compression (Zhao et al., 2015a) (Zhao et al., 2016; Zhao, 2017).

A series of previous studies about the pre-compressed wood confirmed that compression treatment could improve wood penetration and accelerate wood drying. However, few studies on the compression treatment by roller compression method were conducted. And the moisture content changes behavior during both impregnation and drying process by roller compression are still not very clear. The method of roller compression treatment in this study proposed involves passing wood lumber between two compression rollers. The compression roller applies compressive forces to the wood lumber perpendicular to the direction of the wood fiber. The compression method was carried out in a chemical agent, or exposed to atmosphere. The former method can facilitate the chemical penetration on wood skin layer. The latter method aims to modify the structure of wood to improving the fluidity of inner water and shorten drying time.

Wood impregnation modification by preservative or fire retardant and wood drying is the most common operation in wood industry. It is necessary to study the changes of moisture content by roller compression treatment. Therefore, the purpose of this study is to systematically study the MC behavior of Poplar wood by roller compression (RCW), mainly focusing on the effects of compression ratio, compression direction and re-compression times on the reduction of MC. So that clear and enough information can be obtained before practicing the roller compression treatment for wood chemical agent impregnation such preservative or fire retartant, and the following process of wood drying.

\section{MATERIALS AND METHODS}

\section{Materials}

Poplar (Populus ussuriensis Kom.) was purchased from Jilin Provincial Forest Management Bureau Zhengyang Forest Farm. Superior logs with an age of 30-35 years were chosen for this experiment. All of the logs should be $6000 \mathrm{~mm}$ long with $640 \mathrm{~mm}$ small head diameters. Then the logs were sawn into radial and tangential lumber with dimensions of $100 \mathrm{~mm}(\mathrm{~L}) \times 60 \mathrm{~mm}$ $(\mathrm{W}) \times 10 \mathrm{~mm}(\mathrm{~T})$.

\section{Methods}

The roller compression ratios were set at 10\%, 20\%, 30\%, 40\%, and 50\%, respectively. Radial compression was applied to the tangential lumber, while tangential compression was applied to the radial lumber.

Before roller compression, all wood samples were completely oven-dried and then subjected to fully water saturation treatment. In the water saturation treatment, the wood samples were placed in a vacuum pressure tank (with a 0.098 MPa vacuum degree) at room temperature. Using water as a transfer medium, after atmospheric pressure treatment, the vacuum was applied. Wood samples were impregnated at ambient temperature and atmospheric pressure at least 10 days until they were completely saturated with water. Then the MC was calculated around 152\%-168\% based on the oven-dried weight.

\section{Determination of MC changes of RWC samples with different impregnation time}

120 pieces of wood samples with no defect and uniform texture were chosen. All wood samples were subjected fully oven-dried, water saturated, and then weighed in sequence. After that, the samples were divided into 3 groups with 40 blocks in each group. After fully water saturation, Roller compression was then carried out using three compression ratios of $10 \%, 30 \%$, and 50\%, respectively. First, roller compression was carried out, and then the samples were impregnated in water for $0,5,35$, and 95 minutes, respectively. 40 piece wood samples from each group were divided into 4 groups again, then 10 piece samples in each group were treated for one impregnation time.

When the wood samples were taken out, they were dried and weighed immediately. Thus, the MC of each wood sample could be determined based on oven-dried weight. The difference between the MC of the fully water saturated wood samples (W0) and that of the RCW samples with 3 compression ratios at a certain water impregnation time was calculated using the following equation:

$$
T=\frac{W-W_{0}}{W_{0}} \times 100 \%
$$

Where, $T(\%)=$ Percentage change in $\mathrm{MC} ; W(\%)=$ $\mathrm{MC}$ of the RCW sample with 3 compression ratios at a certain impregnation time; $W_{0}(\%)=\mathrm{MC}$ of the totally water saturated wood sample before roller compression treatment.

\section{Determination of MC reduction of RWC samples with different drying time}

Another 60 pieces of radial cutting board and tangential cutting board were chosen and divided into 6 groups (untreated wood sample, and five different compression ratios of $10 \%, 20 \%, 30 \%, 40 \%$, and $50 \%$, respectively). All samples were then heated at $100^{\circ} \mathrm{C}$ in air, and drying time was recorded. The weight of wood samples was determined every half hour until the MC of the wood sample dropped by $10 \%$. After then, they were weighed every an hour until the wood samples were fully dried. 


\section{Determination of MC reduction with different roll-} er re-compression times

Another 50 pieces of the radial cutting board and tangential cutting board were selected and divided into 5 groups. Every 10 pieces with compression ratio of $10 \%$, $20 \%, 30 \%, 40 \%$, and $50 \%$ were carried out $1,3,5$, and 8 times re-compression treatment sequentially. The first roller compression treatment was conducted in water, and then the following re-compression was carried out in air with the same compression ratio. Samples were weighed after totally water saturated treatment $\left(\mathrm{M}_{\mathrm{st}}\right)$ and after each successive round of re-compression (1, 3, 5, and 8 times) $\left(\mathrm{Mr}_{1}, \mathrm{Mr}_{3}, \mathrm{Mr}_{5}\right.$ and $\left.\mathrm{Mr}_{8}\right)$. After the final re-compression treatment, wood samples were oven dried and their final fully oven-dried weights were determined (Woven-dried). Six MCs were recorded with each compression ratio using equation (2).

$$
M C=\frac{m-m_{0}}{m_{0}} \times 100 \%
$$

Where, $M C$ is moisture content; $m$ is the weight of wood samples after re-compression treatment totally water saturated treatment $\left(\mathrm{m}_{\mathrm{st}}\right)$ and after each successive round of re-compression (1, 3, 5, and 8 times) $\left(\mathrm{m}_{\mathrm{r} 1}\right.$, $\mathrm{m}_{\mathrm{r} 3}, \mathrm{~m}_{\mathrm{r} 5}$ and $\left.\mathrm{m}_{\mathrm{r} 8}\right) ; m_{0}$ is the weight of samples after fully oven-dried.

\section{Equipment}

Roller press equipped upper driving roller with rotation speed of $16 \mathrm{r} / \mathrm{min}$ and lower pressing roll with a diameter of $200 \mathrm{~mm}$ were used for compression treatment, as shown in Fig. 1. Constant temperature and humidity chamber (type Climacell 404, MMM, Germany), electrically heated drying oven (type DHG-9075A, Yiheng, Shanghai, China)were used for drying.

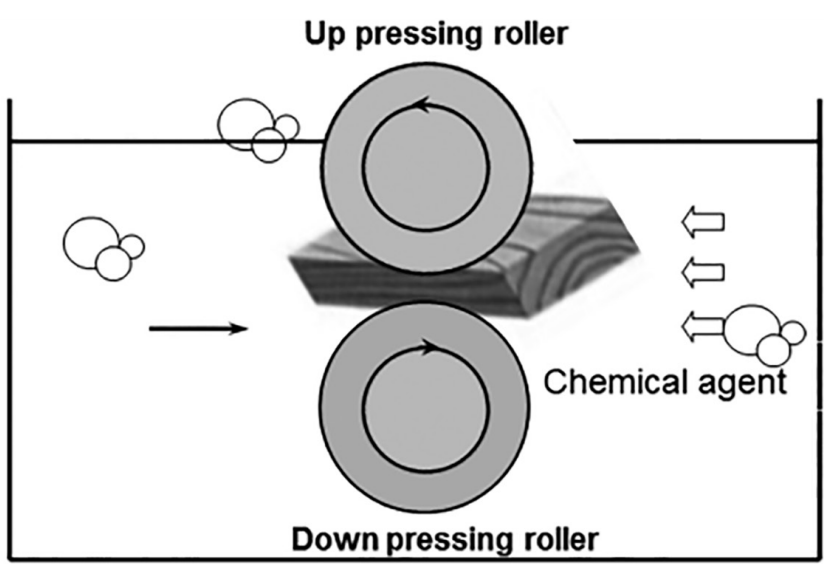

Fig. 1. Roller compression equipment.

\section{RESULTS AND DISCUSSION}

Effect of impregnation time on MC changes of RWC samples with different compression ratios and directions

Generally, water is often used as carrier to facilitate the permeation and transmission of chemical agents during compression and impregnation treatments. Different compression treatment process directly affects the MC changes and chemical modifying impregnation. The compression ratio has obvious effect not only on the efficiency of the treatment, but also on the efficiency of MC changes. This study examined the effects of wood impregnation time in water on MC of Poplar wood samples which treated with different roller compression directions and ratios. The relationship between impregnation time (min) in water and the percentage change in MC were presented in Figs.2 and 3.

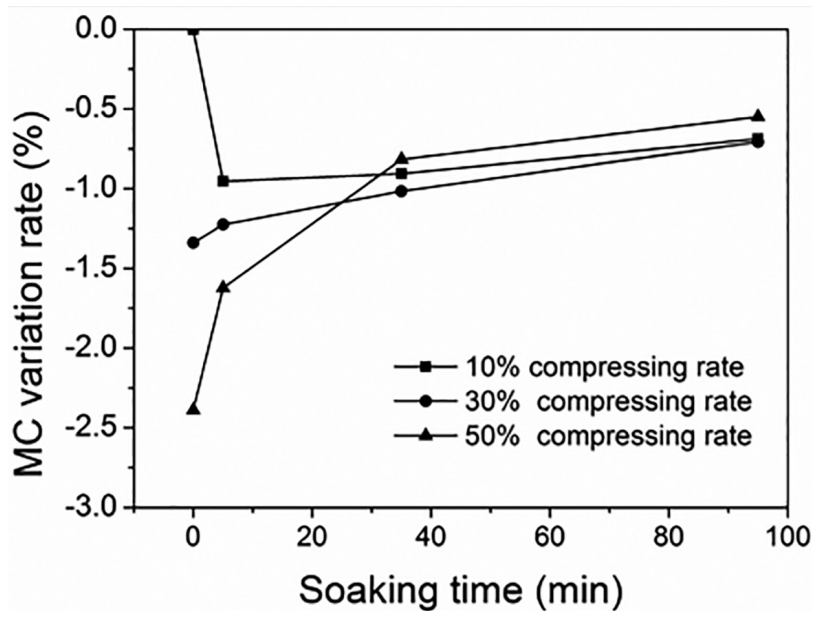

Fig. 2. Effect of impregnation time in water on MC change of RCW samples in radial direction.

Fig. 2 shows the relationship between the change in $\mathrm{MC}$ and impregnation time in the radial compression test with three compression ratios $(10 \%, 30 \%$, and $50 \%)$. It can be seen that the samples with the compression ratio of $10 \%$ did not display a significant change of MC. However, compression ratio of $30 \%$ and $50 \%$ resulted in decreased MC of the RCW samples.

It is attributed that with a lower compression ratio (10\%), the water which lost instant due to compression could be compensated in a short time. Consequently, it is presented slight $\mathrm{MC}$ variation. However, with increasing of compression ratio to $30 \%$ and $50 \%$, the instant compensation of water was slowed down. Therefore, wood samples presented relatively obvious variation of MC. A compression ratio of $30 \%$ in a tangential direction resulted in a 3.0\% decrease in $\mathrm{MC}$, while radial compression only gave a $1.4 \%$ decrease in MC.

In addition, the MC tended to decrease with 10\% compression ratio after 5 minutes impregnation in water. With increasing of compression ratio, the MC in the short period impregnation time (5 min) was slightly lower than untreated samples. With the increasing of impregnation time, the MC increased gradually with different compression ratios. After $95 \mathrm{~min}$ impregnating, the $\mathrm{MC}$ of each compression ratio tended to similar and close to the initial MC. The biggest MC change was $-0.707 \%$. 


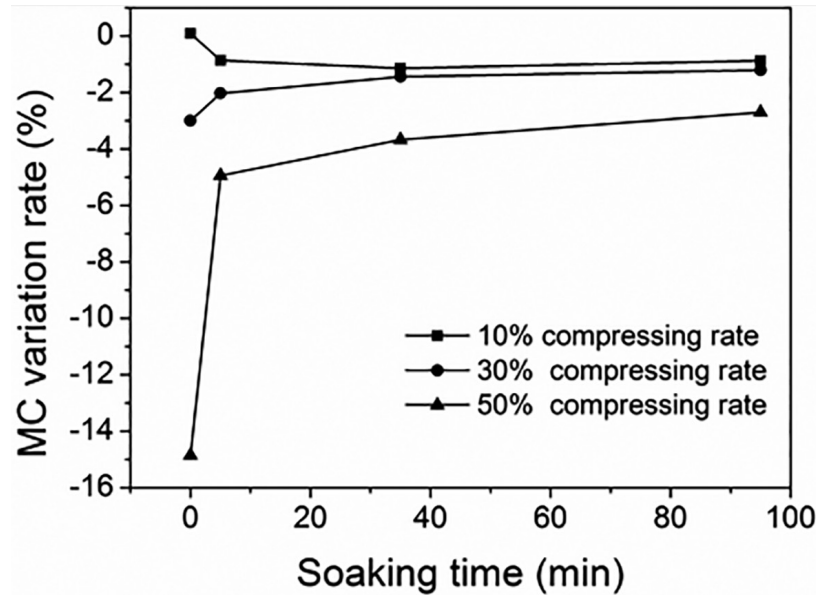

Fig. 3. Effect of impregnation time in water on MC change of RCW samples in tangential direction.

Fig. 3 shows the MC changes in a tangential direction. It was found that the $\mathrm{MC}$ reduction was larger than radial compression. This means that the tangential compression process can squeeze much water out from the wood sample with the same compression ratio. This is due to ray parenchyma cells of the wood matrix are only subjected to axial forces when a radial compression process is employed. This contrasts with the tangential compression process which results in the crack in the wood matrix subjected by lateral forces. In addition, less stress forces were generated for radial compression treatments. It could be considered that radial compression treatments caused more structural deformation, finally led to more water being squeezed out of the wood sample at higher compression ratio.

Moreover, it was found that the MC reduction of RCW samples subjected to high compression ratios occurred more quickly. 50\% compression ratio resulted in $\mathrm{MC}$ decreasing from $14.9 \%$ to $4.9 \%$ after only 5 minutes and then following an increasing trend. The MC of all samples gradually approached the same value after extending impregnation times. As a result, after $95 \mathrm{~min}$ the change in $\mathrm{MC}$ of all RCW samples with different compression ratios were found to be all less $3 \%$.

The results of radial and tangential compression treatment revealed that the MC changes of the Poplar wood samples depended on the compression direction and the impregnation time in water. Prolonged impregnation time resulted in an increase in MC.

\section{Effect of drying time on MC reduction of RWC samples with different compression ratios and directions}

Drying experiments were carried out at $100^{\circ} \mathrm{C}$. The $\mathrm{MC}$ reduction of RCW samples were determined by the equation (2). Average values of MC reduction of RCW samples with different compression ratios, compression directions and impregnation time were determined. The $\mathrm{MC}$ reduction rate can reflect the variation in drying process between the RCW samples and the untreated samples, as shown in Figs. 4 and 5.

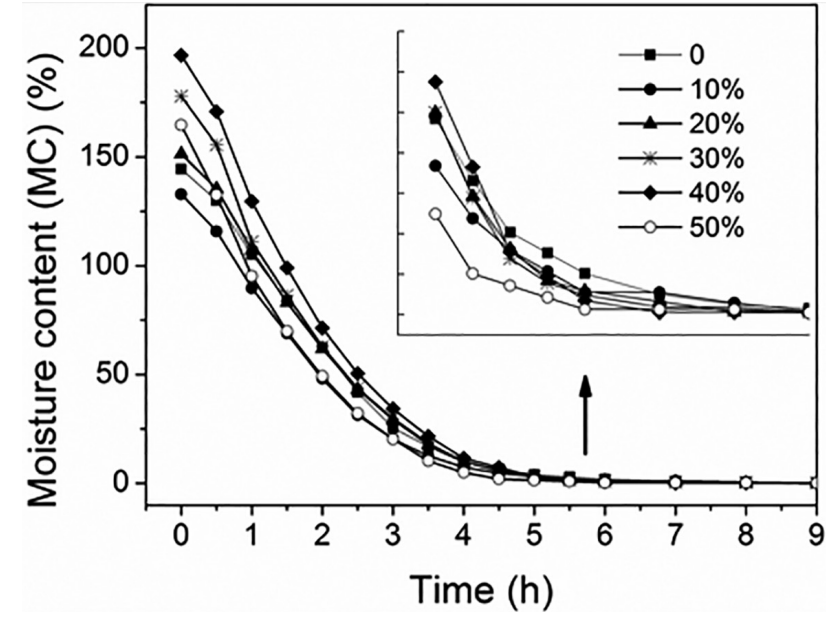

Fig. 4. MC variation of RCW samples by radial compression during drying process.

These results revealed that the rate of MC reduction of RCW samples subjected to both radial and tangential roller compression were less than that of untreated samples. In addition, higher compression ratio resulted in increased MC reduction over shorter periods of time. The MC of tangential boards decreased to 30\% after drying for $3 \mathrm{~h}$. While, for radial boards it was required around $5 \mathrm{~h}$ to reach the same MC level.

As can be seen from the enlarged part of the MC decline curves, the time required for drying to $10 \% \mathrm{MC}$ level were significantly different for RCW samples and untreated samples. The drying times were $4.3 \mathrm{~h}, 4.4 \mathrm{~h}$, $4.0 \mathrm{~h}, 4.2 \mathrm{~h}, 3.5 \mathrm{~h}$, and $4.5 \mathrm{~h}$ for radial compressed samples with compressed ratio of $10 \%, 20 \%, 30 \%, 40 \%$, and $50 \%$ and untreated board samples, respectively. The drying time were decreased by $4.4 \%, 2.2 \%, 11.1 \%, 6.7 \%$ and $22.2 \%$, correspondingly. While, the drying times for RCW samples subjected to tangential compression were reduced by $8.0 \%, 9.3 \%, 13.3 \%, 13.3 \%$ and $24.2 \%$, respectively. In fact, in production longer drying time for larger wood samples is required to remove water. Therefore, the time of RCW saved in drying process should be more obvious in production.

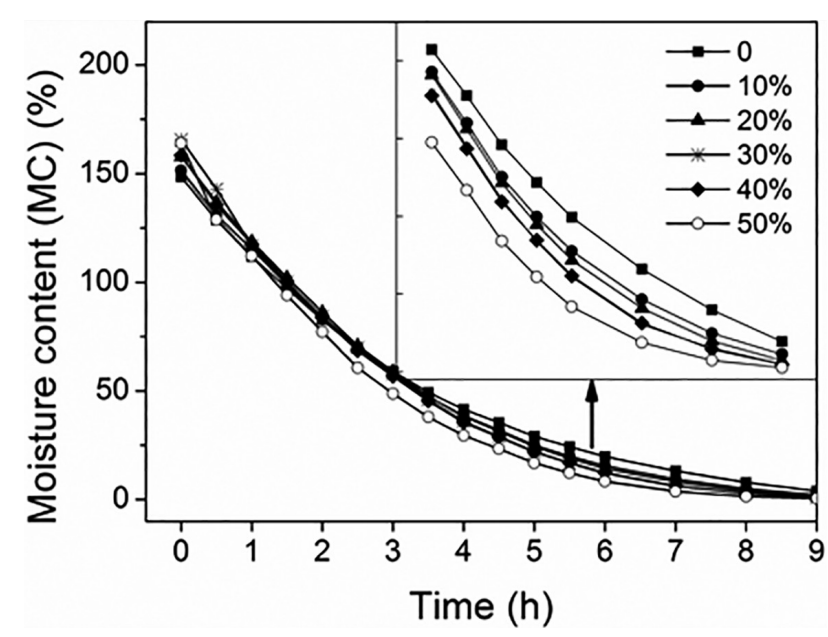

Fig. 5. MC variation of RCW samples by tangential compression during drying process. 
In drying process, the change of MC could directly reflect the difference of $\mathrm{MC}$ decrease rate between untreated samples and RCW samples. As shown in Figs. 4 and 5 , the rate of $\mathrm{MC}$ change is approximately linear until the fiber saturation point (FSP) is reached. Therefore, the rate of MC reduction was calculated from the start of the drying period to the FSP. Radial compression $\mathrm{MC}$ values were calculated from the beginning of the drying to 3 hours, while the tangential compression $\mathrm{MC}$ values were calculated from the beginning to 5 hours.

The rate of MC reduction for RCW samples subjected to radial and tangential compression was shown in Table 1 . The results showed that for both compression modes resulted in MC of RCW samples were lower than that of untreated samples. The results could be explained by Watanabe's found. It was concluded that by compression treatment the cell cavity was totally compressed and the fracture of pit membrane was found on the aspirated pits at the boundary between the torus and margo. Consequently, the compression treatment would improve water transportation and finally facilitate the wood drying and impregnation (Watanabe et al., 1998). The MC reduction of radial compressed RCW samples was much greater than that of tangential compressed RCW samples, which may be related to the difference in the number of pits presented on radial and tangential cell walls.

\section{Effect of roller re-compression times on MC reduction with different compression ratios and directions}

The MC of RCW samples with five compression ratios of $10 \%, 20 \%, 30 \%, 40 \%$, and $50 \%$ was calculated. The corresponding relationships between the MC of the RCW samples with the radial and tangential compression directions are shown in Figs. 6 and 7 .

Overall, the graphs reveal that the MC of RCW samples decreases with increasing re-compression times for each compression ratio. Higher compression ratios lead to water removing faster from wood. Moreover, the rate of $\mathrm{MC}$ decline is more obvious for high compression ratios with the same re-compression times. And the overall reduction was still greater than that of the samples with low compression ratios. When the compression ratio was higher than $40 \%$, the MC of the RCW samples was reduced to half of the initial MC after 3 times re-compression treatment. It is proposed that when re- compression times increased to a certain content, the change of MC tends to be stable even at high compression ratio.

The re-compression treatment process was applied

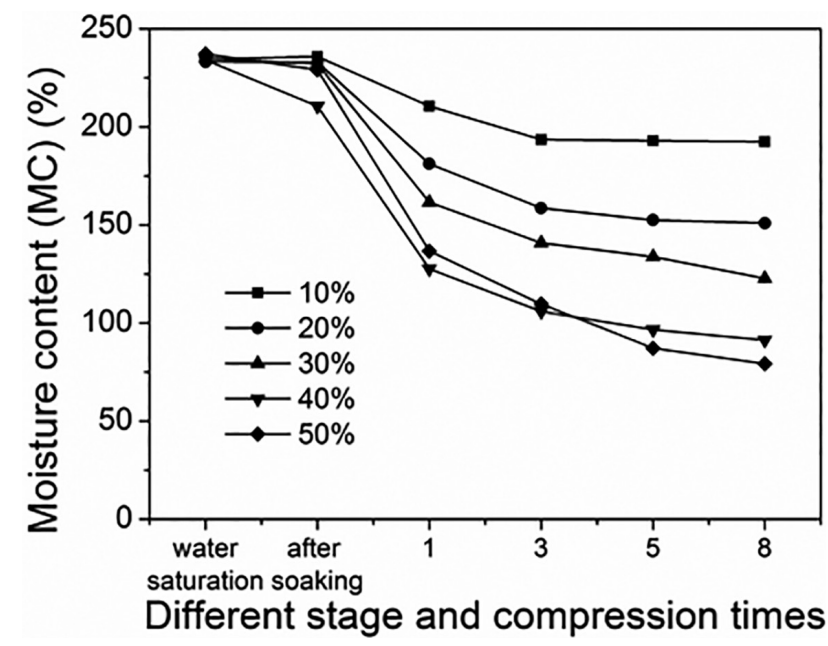

Fig. 6. MC variation of wood samples compressed in radial direction in different experiment stage and re-compression process.

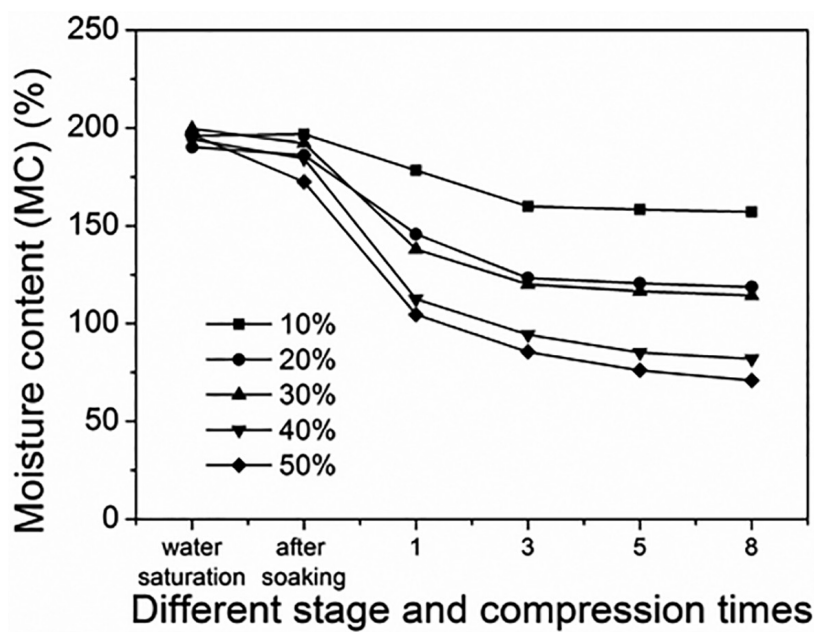

Fig. 7. MC variation of wood samples compressed in tangential direction in different experiment stage and re-compression process.

Table 1. MC reduction of RCW samples

\begin{tabular}{|c|c|c|c|c|}
\hline \multirow{2}{*}{$\begin{array}{l}\text { Compression ratio } \\
\text { (\%) }\end{array}$} & \multicolumn{2}{|c|}{ Radial direction compression } & \multicolumn{2}{|c|}{ Tangential direction compression } \\
\hline & Initial MC (\%) & MC reduction (\%) & Initial MC (\%) & MC reduction (\%) \\
\hline 0 & 144.428 & 39.639 & 148.523 & 23.866 \\
\hline 10 & 132.907 & 37.503 & 151.517 & 25.295 \\
\hline 20 & 151.458 & 40.753 & 157.749 & 26.682 \\
\hline 30 & 177.932 & 49.366 & 165.582 & 28.688 \\
\hline 40 & 196.747 & 54.154 & 158.403 & 27.311 \\
\hline 50 & 164.587 & 48.089 & 163.991 & 29.434 \\
\hline
\end{tabular}


aiming to remove extra water and chemical agents from wood matrix after impregnation process, which could significantly reduce the time and energy consumption in the following drying process. In addition, the re-compression treatment process would reduce the amount and cost of chemical agent used in impregnation. Moreover, an efficient compression process also enables chemical agents to penetrate further into the wood surface, which can significantly increase the thickness of protective layer. Consequently, it is considered that the $\mathrm{MC}$ and chemical agent could be reduced by carrying out roller re-compression treatments at high compression ratios.

\section{CONCLUSIONS}

The MC of RCW samples was decreased with compression ratio increasing. The MC of samples subjected to tangential compression was lower than those of radial compression. Longer impregnation times resulted in the MC of RCW samples increasing gradually. After 5 minutes, the change of MC tended slowly. After 95 minutes, the MC of RCW samples was still lower than that of untreated samples.

The MC decrease rate of RCW samples in the drying process was faster than that of untreated samples. Compared with untreated samples, the time required to dry RCW samples with five different compression ratios to $10 \% \mathrm{MC}$ were less. When the compression ratio was $50 \%$, the time saved was greater than $20 \%$. Higher compression levels lead to faster remove of water from wood samples.

The MC of re-compression treatment samples was found to decrease gradually with increasing re-compression times. In addition, with the same re-compression times, higher compression ratios resulted in more water removed out. With 3 times re-compression, when compression ratio was higher than 40\%, the MC has been reduced to less than half of the initial MC. Therefore, in order to reach a lower MC level, 3 times re-compression with $40 \%$ compression ratio was recommended in roller compression process.

\section{ACKNOWLEDGMENTS}

The authors are grateful for the support of the National Natural Science Foundation of China (31700483) and the Excellent Young Talents Project of Jilin Province (20190103111JH). Thanks are also given to National Natural Science Foundation of China (31470022), and Special plan for Economic Structure Strategic Adjustment in Jilin Province (2015Y079).

\section{REFERENCES}

Bao, F. (1992). "A study on the principle of permeability control of wood." Scientia Silvae Sinicae, 28(4): 336-342

Bao, F., Lu, J., Avramidis, S. (1999). " On the permeability of main wood species in China." Holzforschung, 53(4): 350-354. doi:doi:10.1515/hf.1999.058

Bao, F., Lv, J. (1991). "Effect of microorganism on the permeabil- ity of wood of long white fish scales spruce."Scientia Silvae Sinicae 27(6): 615-622

He, S., Lin, L. Y., Fu, F., Zhou, Y. D., Fan, M. Z. (2014). "Microwave Treatment for Enhancing the Liquid Permeability of Chinese Fir." Bioresources, 9 (2): 1924-1938

Iida, I., Yusuf, S., Watanabe, U., Imamura, Y. (2002). “ Liquid penetration of precompressed wood VII: combined treatment of precompression and extraction in hot water on the liquid penetration of wood." Journal of Wood Science, 48(1): 81-85. doi:10.1007/bf00766243

Keisuke, A., Nobuaki, H. (2011). " Effects of Laser Incising on Lumber Strength I : Partial compression strength of lumber." Wood industry, 48(7): 314-319

Kvist, P., Schuster, E., Loren, N., Rasmuson, A. (2018). "Using fluorescent probes and FRAP to investigate macromolecule diffusion in steam-exploded wood." Wood Science and Technology, 52(5): 1395-1410.doi:10.1007/s00226-018-1039-5

Li, H. H., Zhang, F. M., Ramaswamy, H. S., Zhu, S. M., Yu, Y. (2016). " High-Pressure Treatment of Chinese Fir Wood: Effect on Density, Mechanical Properties, Humidity-Related Moisture Migration, and Dimensional Stability." Bioresources, 11(4): 10497-10510.doi:10.15376/biores.11.4.10497-10510

Lv, J., Bao, F., Jiang, X., Zhao, Y. (2000). " The effect of three different treatment methods on wood permeability."Scientia Silvae Sinicae, $\mathbf{3 6}(4)$ : 67-76

Missio, A. L., de Cademartori, P. H. G., Mottos, B. D., Santini, E. J., Haselein, C. R., Gatto, D. A. (2016). " Physical and Mechanical Properties of Fast-Growing Wood Subjected to Freeze-Heat Treatments." Bioresources, 11(4): 10378-10390.doi:10.15376/ biores.11.4.10378-10390

Missio, A. L., Mattos, B. D., de Cademartori, P. H. G., Gatto, D. A. (2015). " EFFECTS OF TWO-STEP FREEZING-HEAT TREATMENTS ON JAPANESE RAISINTREE (HOVENIA DULCIS THUNB.) WOOD PROPERTIES." Journal of Wood Chemistry and Technology, 36(1): 16-26.doi:10.1080/0277381 3.2015.1039544

Nair, H. U., Simonsen, J. (1995). "The Pressure Treatment of Wood with Sonic Waves." Forest Products Journal, 45(9): 59-64

Watanabe, U., Imamura, Y., Iida, I. (1998). "Liquid penetration of precompressed wood VI: Anatomical characterization of pit fractures." Journal of Wood Science, 44(2): 158-162.doi:10.1007/ bf00526263

Wheat, P. E., Curtis, K. C., Chatrathi, R. S. (1996). " Ultrasonic energy in conjunction with the double-diffusion treating technique." Forest Products Journal, 46(1): 43-48

Xu, J., He, S., Li, J. P., Yu, H., Zhao, S. Q., Chen, Y. H., Ma, L. F. (2018). "Effect of Vacuum Freeze-drying on Enhancing Liquid Permeability of Moso Bamboo." Bioresources, 13(2): 4159_ 4174.doi:10.15376/biores.13.2.4159-4174

Zhang, Y. L., Cai, L. P. (2006). "Effects of steam explosion on wood appearance and structure of sub-alpine fir." Wood Science and Technology, 40(5): 427-436.doi:10.1007/s00226005-0053-6

Zhao, Y., Wang, Z., Iida, I., Huang, R., Lu, J., Jiang, J. (2015a). “ Studies on pre-treatment by compression for wood drying I: effects of compression ratio, compression direction and compression speed on the reduction of moisture content in wood." Journal of Wood Science, 61(2): 113-119.doi:10.1007/s10086014-1451-X

Zhao, Y., Wang, Z., Iida, I., Huang, R., Lu, J., Jiang, J. (2016). "Studies on pre-treatment by compression for wood drying II: effects of compression ratio, compression direction and compression speed on the recovery rate and mechanical properties of wood." Journal of Wood Science, 62(3): 226-232. doi:10.1007/s10086-016-1552-9

Zhao, Y. K. (2017). " Studies on pre-treatment by compression for wood drying III: the reduction of moisture content, the recovery rate, and mechanical properties of wood compressed at different moisture content conditions." Journal of Wood Science, 63(3): 209-215.doi:10.1007/s10086-017-1612-9

Zhao, Y. K., Wang, Z. H., Iida, I., Huang, R. F., Lu, J. X., Jiang, J. H. 
(2015b). " Studies on pre-treatment by compression for wood drying I: effects of compression ratio, compression direction and compression speed on the reduction of moisture content in wood." Journal of Wood Science, 61(2): 113-119.doi:10.1007/ s10086-014-1451-x 
